\title{
CTBP1 and metabolic syndrome induce an mRNA and miRNA expression profile critical for breast cancer progression and metastasis
}

\author{
Paula L. Farré ${ }^{1}$, Georgina D. Scalise ${ }^{1}$, Rocío B. Duca ${ }^{1}$, Guillermo N. Dalton ${ }^{1}$, Cintia \\ Massillo $^{1}$, Juliana Porretti ${ }^{1}$, Karen Graña ${ }^{1}$, Kevin Gardner ${ }^{2}$, Paola De Luca $^{1, *}$ and \\ Adriana De Siervi ${ }^{1, *}$ \\ ${ }^{1}$ Laboratorio de Oncología Molecular y Nuevos Blancos Terapéuticos, Instituto de Biología y Medicina Experimental, CONICET, \\ Buenos Aires, Argentina \\ ${ }^{2}$ Department of Pathology and Cell Biology, Columbia University Medical Center, New York, New York, USA \\ *These authors contributed equally to this work \\ Correspondence to: Adriana De Siervi, email: adesiervi@dna.uba.ar \\ Paola De Luca, email: pdeluca@dna.uba.ar \\ Keywords: CTBP 1; miRNAs; metabolic syndrome; breast cancer; metastasis
}

Received: October 11, $2017 \quad$ Accepted: January 31, 2018 Published: February 13, 2018

Copyright: Farré et al. This is an open-access article distributed under the terms of the Creative Commons Attribution License 3.0 (CC BY 3.0), which permits unrestricted use, distribution, and reproduction in any medium, provided the original author and source are credited.

\section{ABSTRACT}

Metastatic breast cancer (BrCa) is still one of the main causes of cancer death in women. Metabolic syndrome (MeS), a risk factor for $\mathrm{BrCa}$, is associated to high grade tumors, increased metastasis and recurrence of this disease. C-terminal binding protein 1 (CTBP1) is a co-repressor of tumor suppressor genes that is activated by Iow NAD+/NADH ratio. Previously, we demonstrated that CTBP1 hyperactivation by MeS increased tumor growth in MDA-MB-231-derived xenografts regulating several genes and miRNAs. In this work, our aim was to elucidate the role of CTBP1 and MeS in BrCa metastasis. We found that CTBP1 protein diminished adhesion while increased migration of triple negative BrCa cells. CTBP1 and MeS modulated the expression of multiple genes (ITGB4, ITGB6, PRSS2, COL17A1 and FABP4) and miRNAs (miR-378a-3p, miR-146a-5p, let-7e-3p, miR-381-5p, miR-194-5p, miR-494$3 p$ ) involved in BrCa progression of MDA-MB-231-derived xenografts. Furthermore, we demonstrated that MeS increased lung micrometastasis and liver neoplastic disease in mice. CTBP1 hyperactivation seems to be critical for MeS effect on BrCa metastasis since CTBP1 depletion completely impaired the detection of circulating tumor cells. Our results highlight CTBP1 and MeS impact on BrCa progression positioning them as key properties to be considered for BrCa patient prognosis and management.

\section{INTRODUCTION}

Breast cancer $(\mathrm{BrCa})$ is the most common type of cancer in women (aside from skin cancer), and it is the main cause of death between women [1]. Even though cancer is influenced by genetic conditions, there are several risk factors such as diet, overweight and sedentary lifestyle that could be determinant in the development of this disease [2].

According to the National Cholesterol Education Program Adult Treatment Panel III (NCEP ATP III) criteria, metabolic syndrome (MeS) is a cluster of pathophysiological disorders including three or more of the following factors: blood-pressure $\geq 130 / 85 \mathrm{~mm} \mathrm{Hg}$, triglycerides $\geq 150 \mathrm{mg} /$ $\mathrm{dL}$, abdominal obesity (waist circumference $\geq 35$ inches in women), high density lipoprotein (HDL-C) $<50 \mathrm{mg} / \mathrm{dL}$ for women and fasting glucose $\geq 110 \mathrm{mg} / \mathrm{dL}[3,4]$. Recently, a meta-analysis study had shown that MeS is a risk factor for $\mathrm{BrCa}$ in general population [5] having a stronger association in post-menopausal women [6]. Beside this association, a retrospective study demonstrated that $\mathrm{MeS}$ has a major prevalence in triple negative $\mathrm{BrCa}$ (TNBC) rather than in other types [7]. Additionally, $\mathrm{MeS}$ is associated to high grade tumors and higher recurrence rate and metastasis of $\mathrm{BrCa}[8]$. 
Previously, we reported C-terminal binding protein 1 (CTBP1), a transcriptional co-repressor of tumor suppressor genes [9], as a molecular link between MeS and $\mathrm{BrCa}$ [10] or prostate cancer [11]. CTBP1 activation occurs after dimerization produced by $\mathrm{NAD}^{+}$or $\mathrm{NADH}$ binding. CTBP1 has been proposed as a metabolic cellular sensor since it shows a higher affinity for NADH ( $>100$-fold) compared to $\mathrm{NAD}^{+}$[12]. Furthermore, we found that MeS increased postnatal development of mice mammary gland observed as an induction of terminal bulbs number. Moreover, we detected epithelial changes in mammary ducts with high expression of CTBP1 and CCND1 in MeS mice [10]. CTBP1 and MeS increased breast tumor growth regulating several genes and miRNAs involved in cell proliferation, self-renewal, mammary differentiation, cell communication, metabolic processes and epithelial-to-mesenchymal transition (EMT) in orthotopic xenografts [10].

Metastasis is still the main cause of death for $\mathrm{BrCa}$ patients, and around $30 \%$ of women with $\mathrm{BrCa}$ diagnosed at early stages will progress to metastatic stage. The aim of this work was to investigate the role of CTBP1 and $\mathrm{MeS}$ in BrCa metastasis using a MeS experimental model. We found that CTBP1 decreased BrCa cell adhesion and migration through expression modulation of multiple genes and miRNAs involved in $\mathrm{BrCa}$ progression. Moreover, CTBP1 and MeS increased circulating tumor cells (CTCs) and metastasis in nude mice.

\section{RESULTS}

\section{CTBP1 protein regulates cell adhesion and migration of BrCa cells}

To analyze CTBP1 role in breast tumor progression, we first analyzed CTBP1 modulation effect on MDAMB-231, 4T1 and Hs578T BrCa cell adhesion and migration, both cell lines representing advanced stages of TNBC. In vitro cell adhesion assay with or without collagen matrix was performed using stable transfected MDA-MB-231 cells with diminished (shRNA CTBP1) or control (shRNA Scramble) expression of CTBP1. CTBP1 protein and mRNA levels in the transfected cell lines were assessed by WB (Figure 1A) and RT-qPCR (Figure 1B-1C), respectively. CTBP1 depletion increased MDAMB-231 cell adhesion, both in the presence or absence of collagen matrix (Figure 1D, 1E). Additionally, 4T1 and Hs578T cells were transiently transfected with CTBP1 plasmid (pcDNA3 CTBP1) or control (pcDNA3) and cell adhesion was determined. As shown in Figure $1 \mathrm{~F}$ and $1 \mathrm{G}$, CTBP1 significantly decreased Hs578T cell adhesion without changes in 4T1 cells.

Cell migration of MDA-MB-231 CTBP1 depleted cells (Figure 1A) and 4T1 CTBP1 overexpressing cells (Figure 1C) were determined by wound healing assay. We found that CTBP1 depletion decreased wound closure of these cell lines, and in turn, CTBP1 overexpression induced migration (Figure 2A-2D).

In summary, CTBP1 diminished cell adhesion and increased cell migration, both initial processes for tumor progression, in TNBC cells.

\section{CTBP1 and MeS modulate multiple genes and miRNAs involved in BrCa progression}

To study the relevance of CTBP1 and MeS in BrCa progression, female $n u / n u$ mice were chronically fed with control diet (CD) or high fat diet (HFD) and inoculated in the mammary fat pad (MFP) with CTBP1-depleted (shRNA CTBP1) or control (shRNA Scramble) MDAMB-231 cells. Xenograft samples were collected for total RNA isolation and expression of genes involved in key processes for BrCa progression was determined by RT-qPCR. First, mRNA levels of CTBP family members were assessed in order to check that CTBP1 expression was diminished without changes in CTBP2 during the experiment (Figure 3A).

Then, we assessed expression of cell adhesion genes: COL17A1, FABP4, ITGA1, ITGB4, ITGB6, TGM2; cell migration genes: COL17A1, FABP4, ITGB4, ITGB6, PRSS2, TGM2 and cell invasion genes: FABP4, ITGB4, ITGB6, PRSS2, TGM2. We found that CTBP1 significantly modulated ITGB4 and PRSS2 genes while $\mathrm{MeS}$ regulated $C O L 17 A 1$ and FABP4 expression (Figure $3 \mathrm{~A})$. Interestingly, we found that $I T G B 6$ regulation by MeS occurred only in xenografts with high CTBP1 expression (Figure 3A).

Previously, we identified 42 miRNAs involved in metabolism, cell cycle and cell communication, regulated by CTBP1 in BrCa orthotopic xenografts generated in MeS mice [10]. In this work, to elucidate which of these miRNAs could be crucial for $\mathrm{BrCa}$ development and tumor progression, we performed a reactome analysis using the bioinformatic resource miRSystem based on the number of biological processes regulated by each miRNA. We identified a cluster of miRNAs with relevant roles in cell proliferation (miR-378a-3p, miR-146a-5p and miR381 ) and tumor progression (miR-378a-3p, miR-146a-5p, miR-381, miR-223-3p, miR-494-3p, miR-940, miR-433, miR-522 and miR-637) (Supplementary Table 1). Based on this analysis we validated these miRNAs by RT-qPCR. Also, considering their functions in $\mathrm{BrCa}$ progression, we included for further studies let-7e-3p [13] and miR-1941-5p [14], both identified as CTBP1-regulated miRNAs in the microarray. As shown in Figure 3B, using miRNA RT-qPCR we found that CTBP1 modulated miR-4943p, miR-381-5p, miR-378a-3p, let-7e-3p, miR-194-1-5p and miR-146a-5p in MDA-MB-231-derived xenografts (Figure 3B). Furthermore, MeS induced miR-381-5p and miR-194-1-5p expression (Figure 3B). We were not able to validate the expression of miR-940, miR-433-3p and miR-637 by RT-qPCR stem loop method. 
Altogether these results suggest that CTBP1 and $\mathrm{MeS}$ regulate $\mathrm{BrCa}$ progression throughout modulation of multiple genes and miRNAs.

\section{MeS and CTBP1 increase BrCa lung metastases and liver neoplastic disease}

We next analyzed the effect of CTBP1 and MeS on BrCa metastasis. Thus, MeS female nu/nu mice or control were inoculated in the MFP with MDAMB-231 shRNA CTBP1 or shRNA Scramble cells. After 45 days post-injection, lung and liver samples were collected for macroscopic, histological and RT-qPCR analysis. As previously reported for MDA-MB-231 cell line, macroscopic analysis did not reveal the presence of metastasis in all experimental groups; however, hematoxylin and eosin (H\&E) staining and histological analysis allowed detection of micrometastases in both lung and liver. We found that hyperactivation of CTBP1 by $\mathrm{MeS}$ increased the percentage of mice with lung metastases and liver neoplastic disease, which includes hepatic micometastasis and intravascular tumor cells (Figure 4A and Table 1). Moreover, MeS mice inoculated with control cells developed micrometastasis bigger than other groups, suggesting that CTBP1 hyperactivation by $\mathrm{MeS}$ increase both development of metastasis and aggressiveness of secondary tumors (Figure 4A). We also detected human BrCa cells in lungs by RT-qPCR using specific human GAPDH primers. MeS increased the amount of human BrCa cells in lungs, and this effect was enlarged in mice injected with higher CTBP1 expression cells (shRNA Scramble) (Figure 4B). Also, CTCs in mice blood were identified by clonogenic assays (Figure $4 \mathrm{C}$ and Table 2). In agreement to these results, we found that CTBP1-depletion completely impaired CTCs from MeS mice.
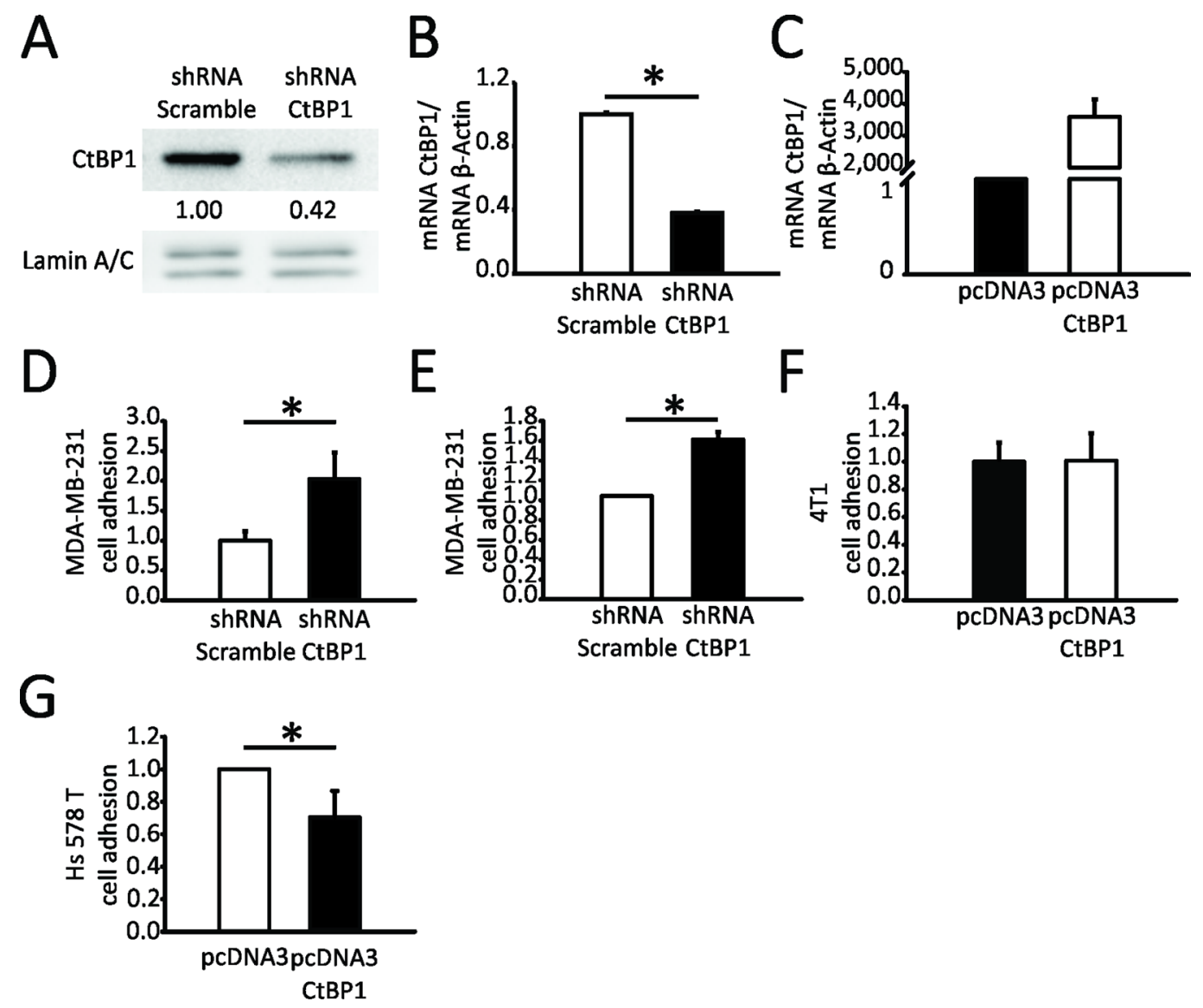

Figure 1: CTBP1 diminishes MDA-MB-231 and Hs578T cell adhesion. CTBP1 expression was determined in MDA-MB-231 CTBP1 stable depleted (shRNA CTBP1) or control (shRNA Scramble) cells by (A) WB and (B) RT-qPCR. WB quantification of each band using Image J software is shown. Data were normalized to LMNA and control cells. CTBP1 mRNA expression levels were normalized to ACTB and control $\left({ }^{*} p\right.$ value $\left.<0.05\right)$. (C) CTBP1 mRNA levels were determined in 4T1 cells transiently transfected with CTBP1 overexpression (pcDNA3 CTBP1) or control (pcDNA3) vectors by RT-qPCR and normalized to ACTB and control. Cell adhesion assay was performed in MDA-MB-231 shRNA CTBP1 or shRNA Scramble cells without (D) or with (E) collagen matrix. The mean and SD of one representative experiment $(n=2)$ with triplicates is shown. Data were normalized to protein and control $\left({ }^{*} p\right.$ value $\left.<0.05\right)$. (F) Cell adhesion assay was performed in 4T1 pcDNA3 CTBP1 or pcDNA3 cells. The mean and SD of one representative experiment $(n=2)$ with triplicates is shown. Data were normalized to control. (G) Cell adhesion assay was performed in Hs578T pcDNA3 CTBP1 or pcDNA3 cells. The mean and SD of one representative experiment $(n=2)$ with triplicates is shown. Data were normalized to control. 
Altogether, these results suggest that CTBP1 and $\mathrm{MeS}$ are key activators of $\mathrm{BrCa}$ progression and metastasis.

\section{DISCUSSION}

Even though $\mathrm{BrCa}$ mortality has been reduced over the last decade [15], metastatic $\mathrm{BrCa}$ is still one of the main causes of cancer death in women, being the improvement in the survival rates of patients with metastatic BrCa a major concern for public health [16]. Once metastasis occurs, BrCa becomes a systemic disease and the 5-year survival rate decreases to $20 \%$ [17]. As well reviewed by Lim et al., the heterogeneity between patients will determine the course of the disease and it is crucial for treatment decisions [16]. Several efforts are being made to elucidate the main sources of this heterogeneity. In addition, we propose that patient health conditions that impact on cancer progression and morbidity, together with their associated molecular targets, should be considered for treatment decisions and therapies development. Based on this, MeS constitutes a health condition related to $\mathrm{BrCa}$ recurrence and metastasis, that might be identified for differential patient management [8]. To understand the molecular mechanism underlying BrCa progression connected to $\mathrm{MeS}$ might be a key aspect for these patients. Previously, we identified CTBP1 hyperactivation by $\mathrm{MeS}$ as an inductor of breast carcinogenesis and tumor growth in mice. In this work, we advocated to the study CTBP1 and MeS role over $\mathrm{BrCa}$ metastasis.

In vitro approaches allowed us to elucidate CTBP1 protein effect on adhesion and migration of TNBC cells. We first demonstrated that CTBP1 protein diminished MDA-MB-231 and Hs578T cell adhesion. Several studies have shown that CTBP1
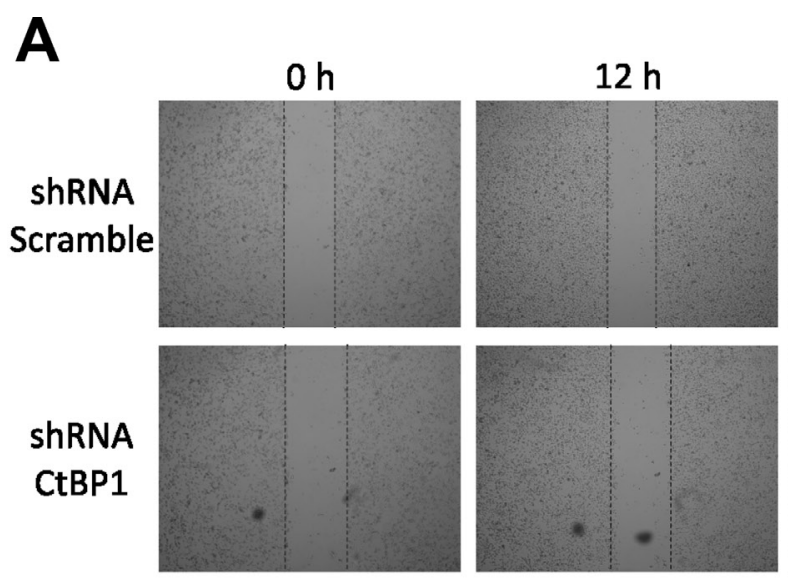

C

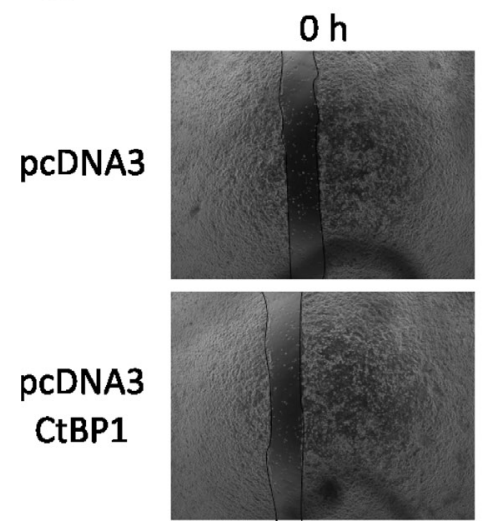

$3 \mathrm{~h}$

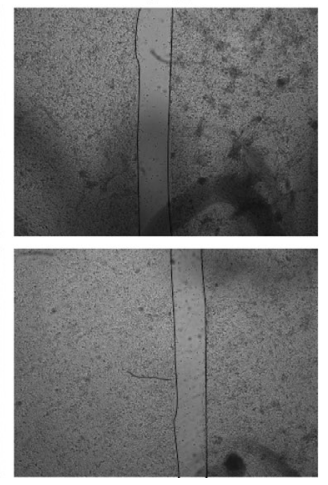

$16 \mathrm{~h}$

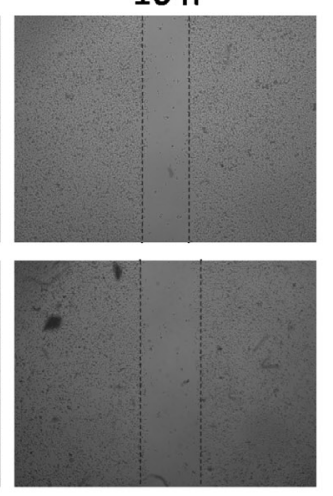

D

\section{$6 \mathrm{~h}$}

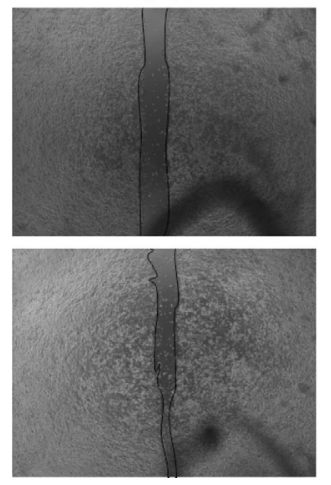

B
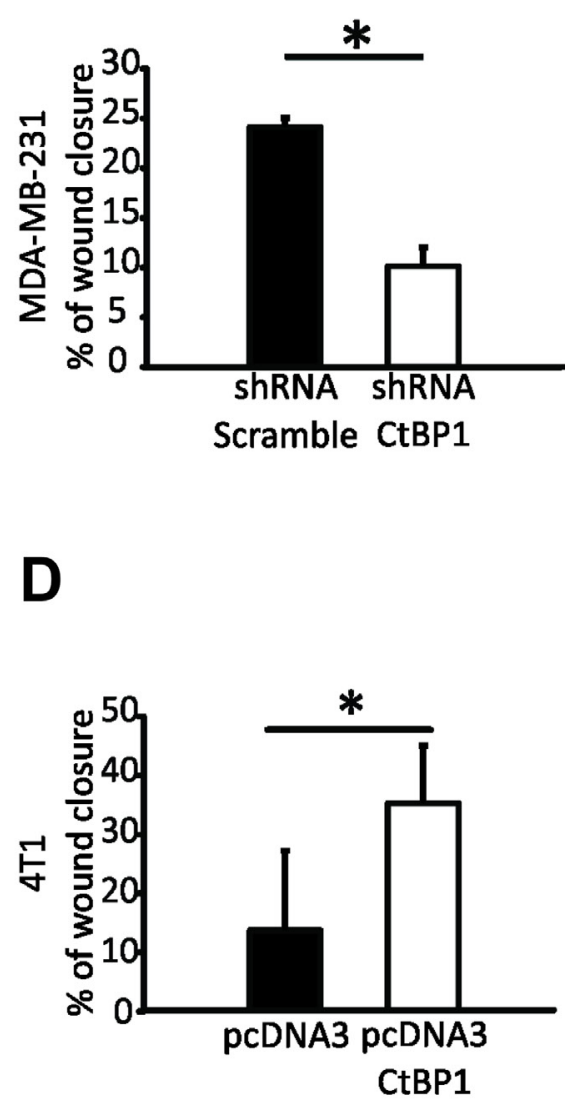

Figure 2: CTBP1 modulates BrCa cell migration. (A) Wound healing assay was performed using MDA-MB-231 CTBP1 stable depleted (shRNA CtBP1) or control (shRNA Scramble) cells. Representative pictures of wound at 0, 12 and $16 \mathrm{~h}$ from 2 independent experiments with triplicates are shown. (B) Percentage of wound closure of MDA-MB-231 shRNA CTBP1 or shRNA Scramble cells is shown as mean and SD of one representative experiment $(n=2)$ with triplicates $\left({ }^{*} p\right.$ value $\left.<0.05\right)$. (C) Wound healing assay was performed using 4T1 pcDNA3 CTBP1 or pcDNA3. Representative pictures of wound at indicated times from 2 independent experiments with triplicates are shown. (D) Percentage of wound closure of 4T1 pcDNA3 CTBP1 or pcDNA3 cells is shown as mean and SD of one representative experiment $(n=2)$ with triplicates $\left({ }^{*} p\right.$ value $\left.<0.05\right)$. 


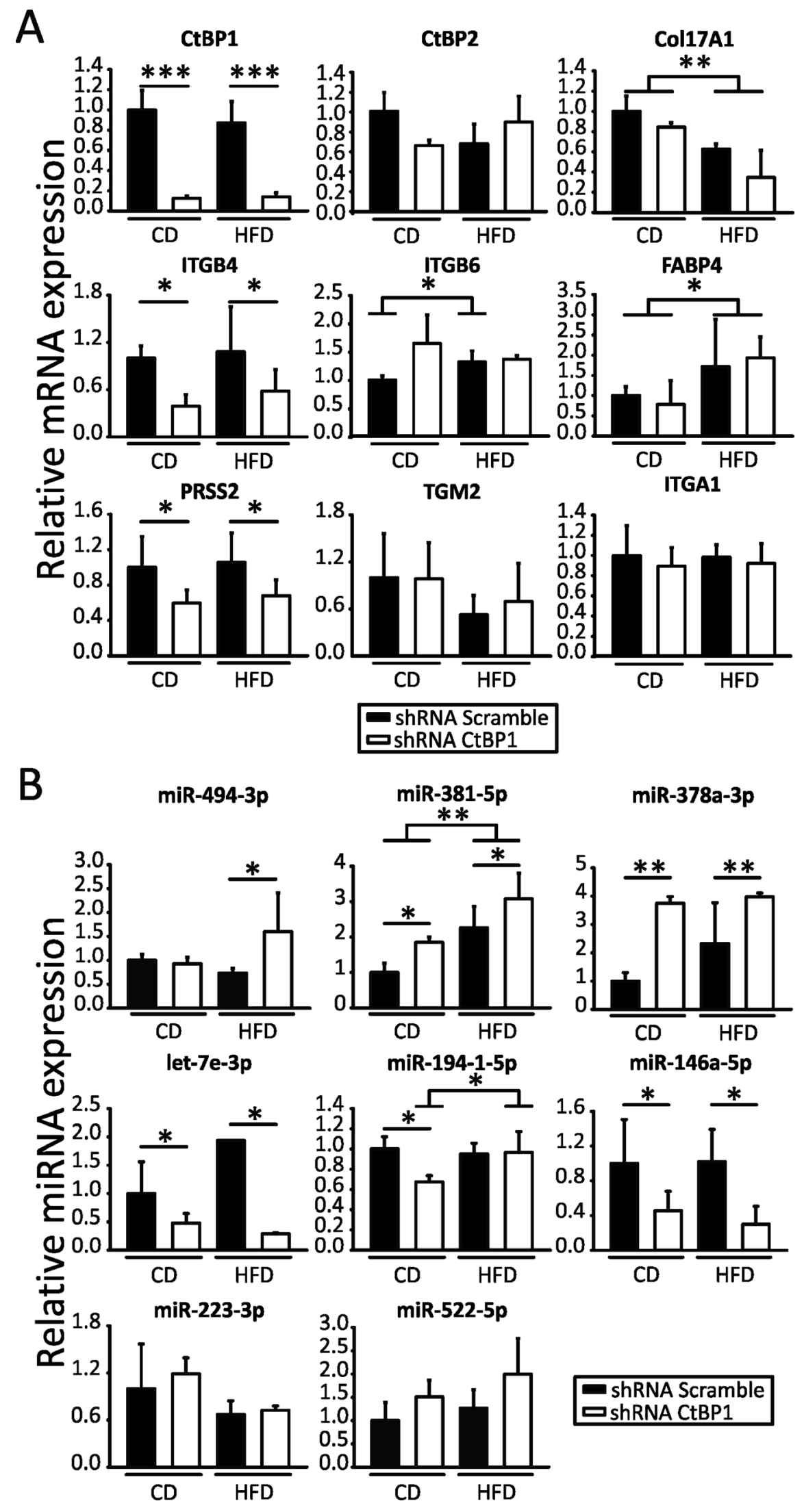

Figure 3: CTBP1 and MeS modulate multiple genes and miRNAs involved in BrCa progression. Expression of the indicated mRNAs (A) and miRNAs (B) in xenografts from CD or HFD mice inoculated with MDA-MB-231 shRNA CTBP1 or shRNA Scramble cells were determined by RT-qPCR using specific primers. Data were normalized to ACTB and control for mRNAs or to geometric mean of miR-103a-3p, miR-191-5p and miR-17-5p and control tumors for miRNAs $\left({ }^{*} p\right.$ value $<0.05 ;{ }^{* *} p$ value $<0.01 ;{ }^{* * *} p$ value $\left.<0.001\right)$. 
Table 1: Quantification of lung metastasis and liver neoplastic disease

\begin{tabular}{lcc}
\hline Experimental group & $\begin{array}{c}\text { Lung metastasis } \\
(\% \text { of mice) }\end{array}$ & $\begin{array}{c}\text { Liver neoplastic disease } \\
\text { (\% of mice) }\end{array}$ \\
\hline shRNA Scramble CD $(n=7)$ & 0 & 14 iv \\
shRNA CTBP1 CD $(n=9)$ & 11 & 0 \\
shRNA Scramble HFD $(n=6)$ & 33 & 33 iv \\
shRNA CTBP1 HFD $(n=7)$ & 14 & 0 \\
\hline
\end{tabular}

Mice were chronically fed with HFD or CD and inoculated with MDA-MB-231 shRNA CTBP1 or shRNA Scramble. Fortyfive days post-injection mice were sacrificed and presence of micrometastasis to lung and liver was determined by histological analysis. Percentage of mice with lung metastasis or liver neoplastic disease of each experimental group is informed. In: intravenous.

modulates the expression of numerous EMT markers, such as E-cadherin, in BrCa cells [9, 10]. Di et al. and Deng et al. demonstrated that CTBP1 induces a mesenchymal phenotype, which is associated with low adhesion, high migration and invasion capabilities through the regulation of multiple genes $[18,19]$. However, this is the first study that demonstrates cell adhesion regulation by CTBP1 in BrCa cells. We also found that CTBP1 protein increased the migratory capability of TNBC MDA-MB-231 and 4T1 cells. These results support previous studies showing that CTBP1 increases migration of hormone sensitive MCF-7 BrCa cells [18] and other cell types such as glioma cancer cells [20].

Previously, we generated a MeS-like experimental model and found that CTBP1 and MeS increased breast tumor growth by regulating multiple genes and miRNAs

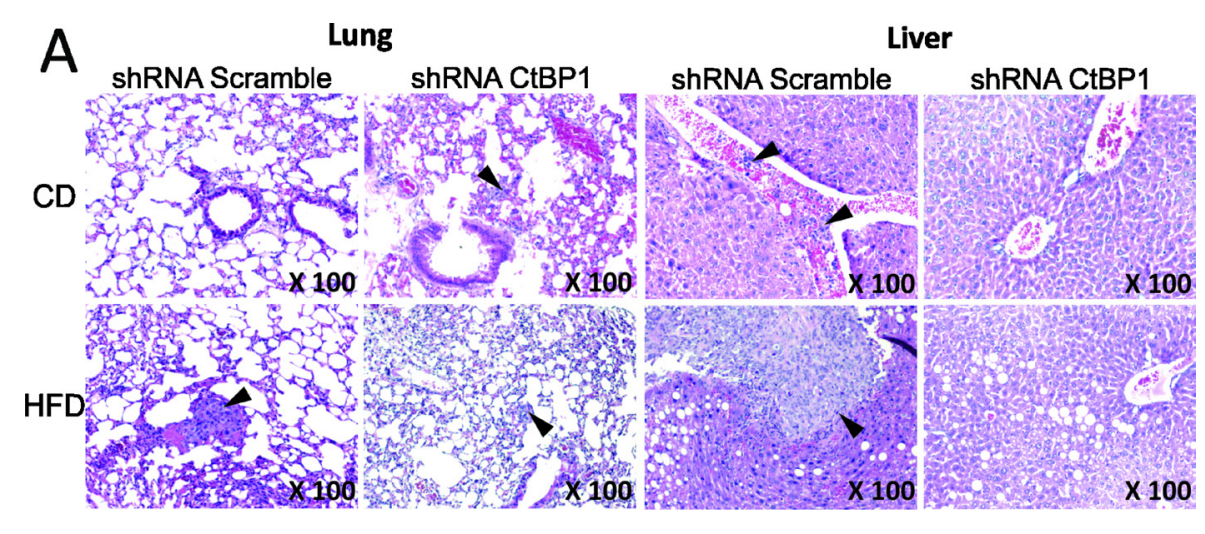

B

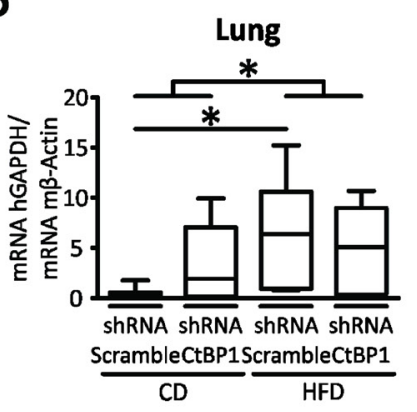

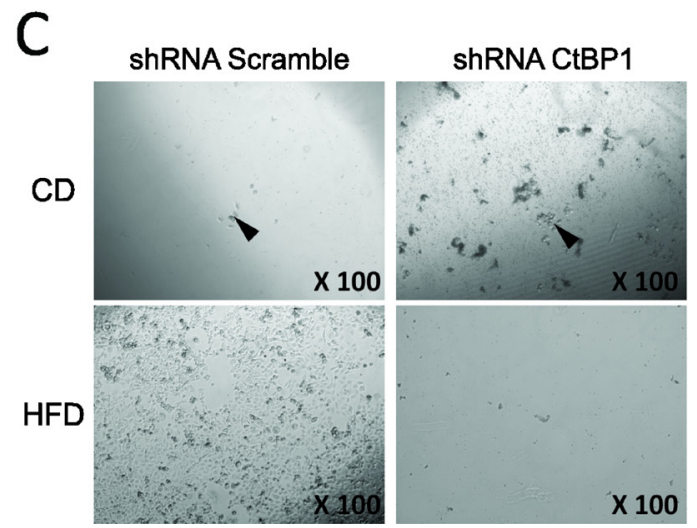

Figure 4: MeS and CTBP1 increase CTCs inducing BrCa lung metastasis and liver neoplastic disease. Mice were fed with CD or HFD and inoculated with MDA-MB-231 shRNA CTBP1 or shRNA Scramble cells. Mice were sacrificed 45 days post-injection and soft tissue and blood samples were collected. (A) Lung and liver H\&E staining is shown. Arrowheads indicate micrometastasis. Magnifications $\times 100$. (B) Presence of human BrCa cells in lung of mice was analyzed by determining human GAPDH expression by RTqPCR using specific human primers. Data were normalized to mouse ACTB $\left({ }^{*} p\right.$ value $\left.<0.05\right)$. (C) Clonogenic assay for detection of CTCs present in blood of mice was performed in medium supplemented with FBS and puromycin $(1 \mu \mathrm{g} / \mathrm{mL})$. Representative pictures are shown (magnifications $\times 100)$. Arrowheads indicate colonies. 
Table 2: Quantification of CTCs from mice

\begin{tabular}{lc}
\hline Experimental group & \% of mice with CTCs \\
\hline shRNA Scramble CD $(n=6)$ & 33 \\
shRNA CTBP1 CD $(n=6)$ & 50 \\
shRNA Scramble HFD $(n=6)$ & 33 \\
shRNA CTBP1 HFD $(n=6)$ & 0 \\
\hline
\end{tabular}

Mice were chronically fed with HFD or CD and inoculated with MDA-MB-231 shRNA CTBP1 or shRNA Scramble. Forty four days post-injection mice were sacrificed and presence of CTCs in blood samples were assessed. Percentage of mice with CTCs of each experimental group is shown.

involved in cell proliferation, progenitor cells phenotype, EMT, mammary development and cell communication [10]. To elucidate CTBP1 and MeS effect on BrCa progression in vivo, here we analyzed expression levels of genes involved in key steps of tumor progression in xenografts generated in the MeS-like model. Moreover, we showed that CTBP1 induced ITGB4 and PRSS2, while MeS regulated $C O L 17 A 1$ and FABP 4 genes. In addition, $\mathrm{MeS}$ induced ITGB6 only in CTBP1-high expression xenografts, suggesting that CTBP1 activation by MeS could be critical for ITGB6 expression. These results support our previous studies showing that, in vivo, CTBP1 and $\mathrm{MeS}$ regulate the mesenchymal markers Vimentin and Slug [10]. Importantly, integrins dysregulation is associated with cancer development and progression, since these are heterodimeric cell surface receptors critical for adhesion, migration, invasion, growth, survival and differentiation [21]. Interestingly, ITGB4 constitutes a marker of basal-like tumors [22] and it is a downstream effector of cell migration mediated by the mesenchymal marker Vimentin [23], which promotes $\mathrm{BrCa}$ invasion through the regulation of cytoskeleton dynamics [24]. Thus, CTBP1 emerges as a master regulator of EMT in $\mathrm{BrCa}$ inducing Vimentin and its downstream target ITGB4. Also, ITGB6 is a known inductor of cell invasion and is a marker of poor prognosis in several cancer types, including $\mathrm{BrCa}$ [25-28]. Altogether, these results suggest that CTBP1 hyperactivation by $\mathrm{MeS}$ is a critical event that might be considered for prognosis assessment in $\mathrm{BrCa}$ patients.

CTBP family proteins are encoded by 2 paralogous genes, CTBP1 and CTBP2. These proteins display redundant functional and structural similarities, although each of them also has many distinct roles. However, both are oncogenic transcriptional co-regulators overexpressed in many cancer types. In this work we found that only CTBP1 gene expression was modified in the tumors without CTBP2 changes which supports the idea that the findings are attributed only to CTBP1.

Previously, we identified 42 miRNAs regulated by CTBP1 from xenografts generated in MeS mice [10]. Here, we selected a cluster of miRNAs from the microarray data based on their function in tumor growth and progression for further validation by miRNA RT-qPCR. We demonstrated that CTBP1 represses miR-378a-3p and miR-494-3p and induces miR-146a-5p and let-7e-3p expression in MDAMB-231 xenografts. Furthermore, CTBP1 and MeS regulate miR-381-5p and miR-194-1-5p expression. These results are consistent with previous studies demonstrating that miR-378a-3p expression is reduced in tumor tissue from $\mathrm{BrCa}$ patients and its expression is associated with better prognosis in $\mathrm{BrCa}$ patients treated with hormone therapy [29]. Also, miR-381-5p expression is reduced in $\mathrm{BrCa}$ compared to adjacent tissue [30]. Moreover, miR-381-5p represses cell proliferation, EMT, invasion and migration of MDA-MB-231 [30], suggesting that one of the mechanisms involved in CTBP1 role in $\mathrm{BrCa}$ adhesion and migration is $\mathrm{miR}-381-5 \mathrm{p}$ repression. Interestingly, miR-194-1-5p, induced by both CTBP1 and MeS, is increased in serum from $\mathrm{BrCa}$ patients with recurrence compared to patients without recurrence [14]. However, other studies determined that miR-146a-5p and let-7e-3p expression, induced by CTBP1 in MDA-MB-231 xenografts, correlates with better survival in BrCa patients [13, 31]. Furthermore, miR-494-3p repressed by CTBP1 hyperactivation by $\mathrm{MeS}$ is increased in patients with metastatic BrCa compared to patients without metastasis [32].

Finally, this is the first report describing CTBP1 role in $\mathrm{BrCa}$ metastasis, and more important how this process can be influenced by MeS. We found that MeS and CTBP1 increased lung micrometastasis and liver neoplastic disease in mice. Importantly, we found that CTBP1 expression is crucial for $\mathrm{BrCa}$ cells to reach the blood stream, since we observed that CTCs, one of the major steps for metastatic cascade, were dramatically decreased by CTBP1-depletion.

In summary, in this work we developed an experimental model that resembles MeS effect on BrCa metastasis. Moreover, we elucidated a molecular mechanism that explains $\mathrm{MeS}$ association with $\mathrm{BrCa}$ metastasis based on metastatic cascade activation by CTBP1 throughout the regulation of multiple EMT-related genes and miRNAs. 


\section{MATERIALS AND METHODS}

\section{Cell culture and transfection}

MDA-MB-231 and Hs578T cells and its derivatives were grown with DMEM medium (GIBCO) supplemented with $10 \%$ of fetal bovine serum (FBS) and antibiotics. Insulin was added to Hs578T cells. 4T1 cells were cultivated with RPMI 1640 medium (Invitrogen) supplemented with $10 \%$ of FBS and antibiotics. Hs578T pcDNA3 CTBP1 and pcDNA3 cells and 4T1 pcDNA3 CTBP1 and pcDNA3 cells were generated by transient transfection as previously described [10]. MDA-MB-231 shRNA Scramble and MDA-MB-231 shRNA CTBP1 stable cell lines were previously generated by lentiviral transduction [10]. Stable transfected cells were selected with $2 \mu \mathrm{g} / \mathrm{mL}$ puromycin (Sigma-Aldrich) for 7 days and then maintained with puromycin $(1 \mu \mathrm{g} / \mathrm{mL})$.

\section{Western blot analysis (WB)}

MDA-MB-231 cells were lysed and immunoblotted as previously described [33] using specific antibodies against CTBP1 (BD Transduction Laboratories) and LMNA (Santa Cruz Biotechnology Inc.) proteins. Protein quantification was performed using Image J 1.48 software.

\section{RNA isolation, cDNA synthesis and qPCR (RT- qPCR)}

Total RNA isolation was performed using Tri Reagent (Genbiotech, Buenos Aires, Argentina). cDNA was synthesized from $2 \mu \mathrm{g}$ of RNA using M-MLV Reverse Transcriptase (Promega). qPCR was performed as previously described [11] using Taq polymerase (Embiotec, Buenos Aires, Argentina) in a StepOne Plus Real Time PCR (Applied Biosystems). Data were normalized to ACTB and control. Primer sequences used are shown in Supplementary Table 2.

\section{miRNA retrotranscription and $q \mathrm{PCR}$ (miRNA RT-qPCR)}

miRNAs were retrotranscribed using stemloop method as previously described [34] with some modifications. Briefly, $100 \mathrm{ng}$ of total RNA were preheated in $14 \mu \mathrm{L}$ containing $0.07 \mu \mathrm{M}$ of stem-loop primer at $70^{\circ} \mathrm{C}$ during $5 \mathrm{~min}$. Then, retrotranscription was performed using M-MLV Reverse Transcriptase (Promega) and incubated in MyGenie96 Thermal Block (Bioneer) for $30 \mathrm{~min}$ at $16^{\circ} \mathrm{C}, 50 \mathrm{~min}$ at $37^{\circ} \mathrm{C}$ and 15 min at $70^{\circ} \mathrm{C}$. qPCR was performed in $25 \mu \mathrm{L}$ with 0.05 $1 \mu \mathrm{L}$ RT product, $1 \mathrm{U}$ Taq DNA polymerase (Pegasus), $4 \mathrm{mM} \mathrm{MgCl}, 0.2 \mathrm{mM}$ dNTPs, $3 \times 10^{-5} \mu \mathrm{L}$ Sybrgreen (Sigma), $0.1 \mu \mathrm{M}$ forward primer and $0.1 \mu \mathrm{M}$ reverse primer. The reactions were incubated in StepOne Plus
Real Time PCR (Applied Biosystems) at $94^{\circ} \mathrm{C}$ for 2 $\mathrm{min}$, followed by 40 cycles of $95^{\circ} \mathrm{C}$ for $15 \mathrm{~s}$, annealing temperature for $20 \mathrm{~s}$ and $72^{\circ} \mathrm{C}$ for $25 \mathrm{~s}$. All reactions were run in duplicate. The expression levels of miRNAs were normalized to the geometric mean of miR-103a-3p, miR191-5p and miR-17a-5p levels as previously described [35]. Primer sequences for miRNA RT-qPCR are listed in Supplementary Table 2.

\section{Cell adhesion assay}

Cell adhesion assay was performed using 96-well tissue culture plates with or without collagen coating as previously described [36]. Briefly, $12 \times 10^{3} \mathrm{MDA}-$ MB-231/Hs578T derived cells or $24 \times 10^{3} 4 \mathrm{~T} 1$ derived cells were incubated in $200 \mu \mathrm{L}$ of medium for 45 or $90 \mathrm{~min}$ at $37^{\circ} \mathrm{C}$, respectively. Then, cells were washed with PBS, fixed with $100 \mu \mathrm{L}$ of methanol, stained with $100 \mu \mathrm{L}$ of $0.5 \%$ crystal violet and washed with PBS. Crystal violet was resuspended in $60 \mu \mathrm{L}$ of $10 \%$ methanol and $5 \%$ glacial acetic acid solution. Absorbance at $620 \mathrm{~nm}$ was determined using an ELISA Multiskan FC (Thermo Scientific). Data were normalized to protein levels from lysates prepared using $1.5 \times 10^{5}$ cells from the plates used for each assay. Collagen coated plates were made by incubation with $200 \mu \mathrm{L}$ of collagen for 1 hour at room temperature.

\section{Wound healing assay}

For wound healing assay, $3 \times 10^{5}$ MDA-MB-231 shRNA Scramble or shRNA CTBP1 cells were seeded in 12 -wells tissue culture plates. After 36 hours, when cells reached confluence, a straight wound line was drawn using a tip and floating cells were removed with PBS washes. For $4 \mathrm{~T} 1$ cells, $5 \times 10^{4}$ cells were seeded in 12 -wells tissue culture plates. After 24 hours, cells were transfected as previously described [10] using $2 \mu \mathrm{g}$ of pcDNA3 or pcDNA3 CTBP1 vectors. Twenty-four hours later, a wound was made as described above. In both cases, cells were maintained in $1 \mathrm{~mL}$ of medium at $37^{\circ} \mathrm{C} 5 \% \mathrm{CO}_{2}$ for 16 hours in the case of MDA-MB-231 cells, or for 9 hours in the case of 4T1 cells. Pictures were obtained using Q-Color5 Digital Camera (OLYMPUS) at the indicated times after scrape and wound closure quantification was performed using ImageJ 1.48 .

\section{MeS murine model and orthotopic xenograft}

Forty-four female $n u / n u$ mice (4 weeks old) were fed ad libitum for 16 weeks with CD $(3120 \mathrm{kcal} / \mathrm{kg}$, $5 \%$ fat, $n=22)$ or HFD (4520 kcal $/ \mathrm{kg}, 37 \%$ fat, $n=22)$ generated supplementing chow food with $32 \%$ of bovine fat first juice (Fatty, Buenos Aires, Argentina) [10]. Body weight was determined once a week. After 10 weeks mice were divided randomly in two subgroups and inoculated with $4.8 \times 10^{6}$ MDA-MB-231 shRNA Scramble or MDAMB-231 shRNA CTBP1 cells in the MFP. Tumor size was 
measured 3 times a week and its volume was calculated as previously described [10]. Six weeks after inoculation mice were sacrificed and tumor, lung, liver and blood samples were collected. IHC and histological analysis were performed in $5 \mu \mathrm{m}$ tissue sections using H\&E. All animal experiments were housed under pathogen free conditions following the IBYME's animal care guidelines.

\section{Tumor and lung tissue samples processing for RT-qPCR}

Tumor and lung samples were homogenized in Tri Reagent (Genbiotech, Buenos Aires, Argentina) using Dremel MultiPro 395 and RNA isolation was performed as previously described [10].

\section{Clonogenic assay and circulating tumor cells (CTCs) detection}

After 42-45 days post-injection, mice blood samples were collected by direct heart puncture and anticoagulated using $60 \mu \mathrm{L} 0.5 \mathrm{M}$ EDTA $\mathrm{pH}=8$. Blood cells were harvested by centrifugation and red blood cells were lysed by 4 rounds of incubation with ammonium chloride potassium (ACK) lysis buffer. Then, blood cells were cultivated in 3 wells of a 12-well tissue culture plate with $750 \mu \mathrm{L}$ of DMEM supplemented with $10 \%$ FBS, $1 \mu \mathrm{g} / \mathrm{mL}$ puromycin and antibiotics for eleven days. Pictures were obtained using Q-Color5 Digital Camera (OLYMPUS).

\section{Statistical analysis}

All results are given as mean and standard deviation (SD) of at least three independent experiments unless stated otherwise. Student $t$ tests were used to ascertain statistical significance with a threshold of $p<0.05$. For $i n$ vivo experiments, two-way ANOVA followed by Tuckey test were performed. Shapiro-Wilk and Levene tests were used to assess normality and homogeneity of variances. ${ }^{*} p<0.05 ;{ }^{* *} p<0.01 ;{ }^{* * *} p<0.001$.

\section{Abbreviations}

ACK: ammonium chloride potassium; BrCa: breast cancer; CD: control diet; CTC: circulating tumor cell; EMT: epithelial-to- mesenchimal transition; FBS: fetal bovine serum; HDL-C: high density lipoprotein cholesterol; HFD: high fat diet; H\&E: hematoxylin and eosin; MFP: mammary fat pad; miRNA: microRNA; $\mathrm{MeS}$ : metabolic syndrome; $\mathrm{NAD}^{+}$: oxidized nicotinamid adenin dinucleotid; NADH: reduced nicotinamid adenin dinucleotid; RT-qPCR: reverse transcription polymerase chain reaction; TNBC: triple negative breast cancer; WB: western blot.

\section{ACKNOWLEDGMENTS AND FUNDING}

This research was supported by the Argentinean Agency of Science and Technology (ANPCyT PICT 2014-324; ANPCyT PICT 2013-2151; ANPCyT PICT 2015-1345). We thank Fundación Williams (Argentina) and Fundación Rene Barón (Argentina) for their support. This work was part of undergraduate thesis of Paula Lucía Farré supported by NCI fellowship from Argentina (2016).

\section{CONFLICTS OF INTEREST}

The authors declare no conflicts of interest

\section{REFERENCES}

1. Siegel RL, Miller KD, Jemal A. Cancer statistics, 2017. CA Cancer J Clin. 2017; 67:7-30. https://doi.org/10.3322/ caac. 21387.

2. Kerr J, Anderson C, Lippman SM. Physical activity, sedentary behaviour, diet, and cancer: an update and emerging new evidence. Lancet Oncol. 2017; 18:e457-71. https://doi.org/10.1016/S1470-2045(17)30411-4.

3. National Cholesterol Education Program (NCEP) Expert Panel on Detection, Evaluation, and Treatment of High Blood Cholesterol in Adults (Adult Treatment Panel III). Third Report of the National Cholesterol Education Program (NCEP) Expert Panel on Detection, Evaluation, and Treatment of High Blood Cholesterol in Adults (Adult Treatment Panel III) final report. Communication. 2002; 106:3143-421.

4. Huang PL. A comprehensive definition for metabolic syndrome. Dis Model Mech. 2009; 2:231-7. https://doi. org/10.1242/dmm.001180.

5. Bhandari R, Kelley GA, Hartley TA, Rockett IR. Metabolic syndrome is associated with increased breast cancer risk: a systematic review with meta-analysis. Int J Breast Cancer. 2014; 2014:189384. https://doi.org/10.1155/2014/189384.

6. Capasso I, Esposito E, Pentimalli F, Crispo A, Montella M, Grimaldi M, De Marco M, Cavalcanti E, D'Aiuto M, Fucito A, Frasci G, Maurea N, Esposito G, et al. Metabolic syndrome affects breast cancer risk in postmenopausal women: National Cancer Institute of Naples experience. Cancer Biol Ther. 2010; 10:1240-3.

7. Maiti B, Kundranda MN, Spiro TP, Daw HA. The association of metabolic syndrome with triple-negative breast cancer. Breast Cancer Res Treat. 2010; 121:479-83. https://doi.org/10.1007/s10549-009-0591-y.

8. Cao L, Yao G, Hu X, Chen L, Ye C. [Advances in studies on metabolic syndrome and breast cancer]. [Article in Chinese]. Zhonghua Wai Ke Za Zhi. 2015; 53:966-9.

9. Chinnadurai G. The Transcriptional Corepressor CtBP: A Foe of Multiple Tumor Suppressors. Cancer Res. 
2009; 69:731-4. https://doi.org/10.1158/0008-5472. CAN-08-3349.

10. De Luca P, Dalton GN, Scalise GD, Moiola CP, Porretti J, Massillo C, Kordon E, Gardner K, Zalazar F, Flumian C, Todaro L, Vazquez ES, Meiss R, De Siervi A. CtBP1 associates metabolic syndrome and breast carcinogenesis targeting multiple miRNAs. Oncotarget. 2016; 7:18798811. https://doi.org/10.18632/oncotarget.7711.

11. Moiola CP, De Luca P, Zalazar F, Cotignola J, RodríguezSeguí SA, Gardner K, Meiss R, Vallecorsa P, Pignataro O, Mazza O, Vazquez ES, De Siervi A. Prostate tumor growth is impaired by CtBP1 depletion in high-fat dietfed mice. Clin Cancer Res. 2014; 20:4086-95. https://doi. org/10.1158/1078-0432.CCR-14-0322.

12. Fjeld CC, Birdsong WT, Goodman RH. Differential binding of $\mathrm{NAD}+$ and $\mathrm{NADH}$ allows the transcriptional corepressor carboxyl-terminal binding protein to serve as a metabolic sensor. Proc Natl Acad Sci. 2003; 100:9202-7. https://doi. org/10.1073/pnas.1633591100.

13. Aure MR, Leivonen SK, Fleischer T, Zhu Q, Overgaard J, Alsner J, Tramm T, Louhimo R, Alnæs GI, Perälä M, Busato $\mathrm{F}$, Touleimat $\mathrm{N}$, Tost $\mathrm{J}$, et al. Individual and combined effects of DNA methylation and copy number alterations on miRNA expression in breast tumors. Genome Biol. 2013; 14:R126. https://doi.org/10.1186/gb-2013-14-11-r126.

14. Huo D, Clayton WM, Yoshimatsu TF, Chen J, Olopade OI. Identification of a circulating microRNA signature to distinguish recurrence in breast cancer patients. Oncotarget. 2016; 7:55231-48. https://doi.org/10.18632/ oncotarget. 10485 .

15. Hanahan D, Weinberg RA. Hallmarks of Cancer: The Next Generation. Cell. 2011; 144:646-74. https://doi. org/10.1016/j.cell.2011.02.013.

16. Lim B, Hortobagyi GN. Current challenges of metastatic breast cancer. Cancer Metastasis Rev. 2016; 35:495-514. https://doi.org/10.1007/s10555-016-9636-y.

17. Yardley DA. Visceral disease in patients with metastatic breast cancer: efficacy and safety of treatment with ixabepilone and other chemotherapeutic agents. Clin Breast Cancer. 2010; 10:64-73. https://doi.org/10.3816/CBC.2010.n.009.

18. Di LJ, Byun JS, Wong MM, Wakano C, Taylor T, Bilke S, Baek S, Hunter K, Yang H, Lee M, Zvosec C, Khramtsova G, Cheng F, et al. Genome-wide profiles of CtBP link metabolism with genome stability and epithelial reprogramming in breast cancer. Nat Commun. 2013; 4:1449. https://doi.org/10.1038/ncomms2438.

19. Deng Y, Deng H, Liu J, Han G, Malkoski S, Liu B, Zhao R, Wang XJ, Zhang Q. Transcriptional down-regulation of Brcal and E-cadherin by CtBP1 in breast cancer. Mol Carcinog. 2012; 51:500-7. https://doi.org/10.1002/mc.20813.

20. Zhao C, Shen Y, Tao X, Xu J, Lu J, Liu C, Xu Z, Tang Q, Tao T, Zhang X. Silencing of CtBP1 suppresses the migration in human glioma cells. J Mol Histol. 2016; 47:297-304. https://doi.org/10.1007/s10735-016-9678-z.
21. Hu M, Yao J, Carroll DK, Weremowicz S, Chen H, Carrasco D, Richardson A, Violette S, Nikolskaya T, Nikolsky Y, Bauerlein EL, Hahn WC, Gelman RS, et al. Regulation of in situ to invasive breast carcinoma transition. Cancer Cell. 2008; 13:394-406. https://doi.org/10.1016/j. ccr.2008.03.007.

22. Lu S, Simin K, Khan A, Mercurio AM. Analysis of integrin beta4 expression in human breast cancer: association with basal-like tumors and prognostic significance. Clin Cancer Res. 2008; 14:1050-8. https://doi.org/10.1158/1078-0432. CCR-07-4116.

23. Vuoriluoto K, Haugen H, Kiviluoto S, Mpindi JP, Nevo J, Gjerdrum C, Tiron C, Lorens JB, Ivaska J. Vimentin regulates EMT induction by Slug and oncogenic H-Ras and migration by governing Axl expression in breast cancer. Oncogene. 2011; 30:1436-48. https://doi.org/10.1038/ onc.2010.509.

24. Gerson KD, Shearstone JR, Maddula VS, Seligmann BE, Mercurio AM. Integrin $\beta 4$ Regulates SPARC Protein to Promote Invasion. J Biol Chem. 2012; 287:9835-44. https:// doi.org/10.1074/jbc.M111.317727.

25. Hazelbag S, Kenter GG, Gorter A, Dreef EJ, Koopman LA, Violette SM, Weinreb PH, Fleuren GJ. Overexpression of the alpha $\mathrm{v}$ beta 6 integrin in cervical squamous cell carcinoma is a prognostic factor for decreased survival. J Pathol. 2007; 212:316-24. https://doi.org/10.1002/ path.2168.

26. Bates RC, Bellovin DI, Brown C, Maynard E, Wu B, Kawakatsu H, Sheppard D, Oettgen P, Mercurio AM. Transcriptional activation of integrin beta6 during the epithelial-mesenchymal transition defines a novel prognostic indicator of aggressive colon carcinoma. J Clin Invest. 2005; 115:339-47. https://doi.org/10.1172/ JCI23183.

27. Elayadi AN, Samli KN, Prudkin L, Liu YH, Bian A, Xie XJ, Wistuba II, Roth JA, McGuire MJ, Brown KC. A peptide selected by biopanning identifies the integrin alphavbeta6 as a prognostic biomarker for nonsmall cell lung cancer. Cancer Res. 2007; 67:5889-95. https://doi. org/10.1158/0008-5472.CAN-07-0245.

28. Desai K, Nair MG, Prabhu JS, Vinod A, Korlimarla A, Rajarajan S, Aiyappa R, Kaluve RS, Alexander A, Hari PS, Mukherjee G, Kumar RV, Manjunath S, et al. High expression of integrin $\beta 6$ in association with the Rho-Rac pathway identifies a poor prognostic subgroup within HER2 amplified breast cancers. Cancer Med. 2016; 5:2000-11. https://doi.org/10.1002/cam4.756.

29. Ikeda K, Horie-Inoue K, Ueno T, Suzuki T, Sato W, Shigekawa T, Osaki A, Saeki T, Berezikov E, Mano H, Inoue S. miR-378a-3p modulates tamoxifen sensitivity in breast cancer MCF-7 cells through targeting GOLT1A. Sci Rep. 2015; 5:13170. https://doi.org/10.1038/srep13170.

30. Xue Y, Xu W, Zhao W, Wang W, Zhang D, Wu P. miR381 inhibited breast cancer cells proliferation, epithelialto-mesenchymal transition and metastasis by targeting 
CXCR4. Biomed Pharmacother. 2017; 86:426-33. https:// doi.org/10.1016/j.biopha.2016.12.051.

31. Zavala V, Pérez-Moreno E, Tapia T, Camus M, Carvallo P. miR-146a and miR-638 in BRCA1-deficient triple negative breast cancer tumors, as potential biomarkers for improved overall survival. Cancer Biomarkers. 2016; 16:99-107. https://doi.org/10.3233/CBM-150545.

32. Marino AL, Evangelista AF, Vieira RA, Macedo T, Kerr LM, Abrahão-Machado LF, Longatto-Filho A, Silveira HC, Marques MM. MicroRNA expression as risk biomarker of breast cancer metastasis: a pilot retrospective casecohort study. BMC Cancer. 2014; 14:739. https://doi. org/10.1186/1471-2407-14-739.

33. De Luca P, Vazquez ES, Moiola CP, Zalazar F, Cotignola J, Gueron G, Gardner K, De Siervi A. BRCA1 loss induces GADD153-mediated doxorubicin resistance in prostate cancer. Mol Cancer Res. 2011; 9:1078-90. https://doi. org/10.1158/1541-7786.MCR-11-0155.
34. Chen C, Ridzon DA, Broomer AJ, Zhou Z, Lee DH, Nguyen JT, Barbisin M, Xu NL, Mahuvakar VR, Andersen MR, Lao KQ, Livak KJ, Guegler KJ. Real-time quantification of microRNAs by stem-loop RT-PCR. Nucleic Acids Res. 2005; 33:e179. https://doi.org/10.1093/nar/gni178.

35. Peltier HJ, Latham GJ. Normalization of microRNA expression levels in quantitative RT-PCR assays: Identification of suitable reference RNA targets in normal and cancerous human solid tissues. RNA. 2008; 14:844-52. https://doi.org/10.1261/rna.939908.

36. Fernández NB, Lorenzo D, Picco ME, Barbero G, DerganDylon LS, Marks MP, García-Rivello H, Gimenez L, Labovsky V, Grumolato L, Lopez-Bergami P. ROR1 contributes to melanoma cell growth and migration by regulating $\mathrm{N}$-cadherin expression via the PI3K/Akt pathway. Mol Carcinog. 2016; 55:1772-85. https://doi. org/10.1002/mc.22426. 